\title{
Retraction Note to: Sparse tensor CCA for color face recognition
}

\author{
Shucheng Huang $\cdot$ Jian Chen $\cdot$ Zhi Luo
}

Published online: 22 October 2014

(C) The Natural Computing Applications Forum 2014

Retraction Note to: Neural Comput \& Applic (2014)

\section{4:1647-1658}

DOI 10.1007/s00521-013-1387-x

The article published in Neural Computing and Applications, Volume 24, Issues 7-8, pages 1647-1658, doi:10.1007/s00521-013-1387-x has been retracted by the Editor-in-Chief, with the agreement of the authors, because it contains significant parts plagiarizing another article.

The online version of the original article can be found under doi:10.1007/s00521-013-1387-x.

S. Huang $(\bowtie) \cdot$ J. Chen $\cdot$ Z. Luo

School of Computer Science and Engineering, Jiangsu

University of Science and Technology, Zhenjiang 212003, China

e-mail: schuang6@126.com 